\title{
Real World Application of Stenting of Unprotected Left Main Coronary Stenosis: A Single-Center Experience
}

\author{
Calvin C. Leunga, ${ }^{\mathrm{a}}$, Timothy C. Ball ${ }^{\mathrm{b}}$, Mandeep S. Sidhu ${ }^{\mathrm{b}}$, James T. DeVries ${ }^{\mathrm{b}}$, John E. Jayne ${ }^{\mathrm{b}}$, \\ John F. Robb ${ }^{\mathrm{b}}$, Aaron V. Kaplan ${ }^{\mathrm{b}}$, Jeremiah R. Brown', \\ David J. Malenka ${ }^{\mathrm{b}}$, Craig A. Thompson ${ }^{\mathrm{d}}$
}

\begin{abstract}
Background: The aim of this study was to summarize our singlecenter real-world experience with percutaneous coronary intervention (PCI) stenting of unprotected left main coronary artery (ULMCA). PCI-stenting of the ULMCA, while controversial, is emerging as an alternative to coronary artery bypass graft $(\mathrm{CABG})$ surgery in select patients and clinical situations.
\end{abstract}

Methods: Between January 2005 and December 2008, PCI-stenting was performed on 125 patients with ULMCA lesions at our institution. Clinical and procedural data were recorded at the time of procedure, and patients were followed prospectively (mean 1.7 years; range 1 day-4.1 years) for outcomes, including death, myocardial infarction (MI), and target vessel revascularization (TVR).

Results: The majority of cases were urgent or emergent $(82.5 \%)$, $50.4 \%$ of patients were non-surgical candidates, and $63.2 \%$ had 3 vessel disease. Many emergent patients presented in shock $(62.1 \%)$, were not surgical candidates $(89.7 \%)$, and had high mortality $(20.7 \%$ in-hospital, $44.8 \%$ long-term). Mortality in the elective group was $6.3 \%$. Cumulative death and TVR rates were $28.8 \%$ and $13.6 \%$, respectively. Independent predictors of mortality were ejection fraction $(\mathrm{EF}) \leq 35 \%$ (HR 2.4, CI 1.1 - 5.4) and left main bifurcation (HR 2.7, CI 1.2 - 5.7).

Conclusions: PCI-stenting is a viable option in patients with

Manuscript accepted for publication April 10, 2012

${ }^{a}$ Section of Cardiology, Department of Medicine, University of South Florida, Tampa, FL, USA

${ }^{\mathrm{b}}$ Section of Cardiology, Department of Medicine, Dartmouth-Hitchcock Medical Center, Lebanon, NH, USA

${ }^{\mathrm{c}}$ The Dartmouth Institute for Health Policy and Clinical Practice, Lebanon, NH, USA

${ }^{\mathrm{d}}$ Yale University School of Medicine, New Haven, CT, USA

${ }^{\mathrm{e}}$ Corresponding author: Calvin C. Leung, Section of Cardiology,

University of South Florida, 2 Tampa General Circle, 5th Floor,

Tampa, FL 33606, USA. Email: cleung1@health.usf.edu

doi:10.4021/cr165w
LMCA disease and extends options to patients who are poor candidates for CABG. Elective PCI in low-risk CABG patients results in good long-term survival. Cumulative TVR is $13.6 \%$. EF $\leq 35 \%$ and left main bifurcation are independently associated with increased mortality.

Keywords: Cardiac catheterization; Left main coronary artery; Percutaneous intervention; Stenting

\section{Introduction}

Left main coronary artery (LMCA) stenoses are found in $3-10 \%$ of patients undergoing coronary angiography $[1,2]$. Medical treatment results in one year mortality of $21 \%$ [3] and three year mortality of 30-40\% [4-7]. Coronary artery bypass graft surgery (CABG) leads to improved long-term survival [4-7] and continues to be the recommendation for the treatment of unprotected LMCA lesions [8]. ULMCA PCI has been upgraded to a Class IIb recommendation according to American College of Cardiology/American Heart Association guidelines for patients not suitable for CABG.

\section{Methods}

\section{Study design}

This is a prospective registry study looking at patients in a "real world" application undergoing PCI-stenting of LMCA lesions at Dartmouth-Hitchcock Medical Center, an academic rural regional medical center. Patients were identified at the time of the procedure with demographic, clinical, angiographic, and procedural data and followed prospectively in the Dartmouth Dynamic Registry, which has been approved by the Institutional Review Board (Dartmouth Center for the Protection of Human Subjects).

\section{Study population}

Patients were included in the study if they had PCI-stenting 
Table 1. Characteristics for All Patients and Comparison of Bifurcation and Non-Bifurcation Cohorts

\begin{tabular}{|c|c|c|c|c|}
\hline Variables & All & Bifurcation & $\begin{array}{l}\text { Non- } \\
\text { bifurcation }\end{array}$ & P-value \\
\hline Number $(\mathrm{N}=125)$ & $125(100 \%)$ & $64(51.2 \%)$ & $61(48.8 \%)$ & \\
\hline \multicolumn{5}{|l|}{ Demographics } \\
\hline Age (years) & $73.7 \pm 10.9$ & $73.9 \pm 11.0$ & $73.5 \pm 10.9$ & 0.85 \\
\hline Gender (female; \%) & 40.8 & 39.1 & 42.6 & 0.69 \\
\hline Body mass index & $28.2 \pm 6.7$ & $28.3 \pm 6.6$ & $28.0 \pm 6.9$ & 0.79 \\
\hline \multicolumn{5}{|l|}{ Co-morbidities } \\
\hline Chronic obstructive pulmonary disease $(\%)$ & 20.0 & 18.8 & 21.3 & 0.72 \\
\hline Peripheral vascular disease (\%) & 34.4 & 37.5 & 31.2 & 0.46 \\
\hline Baseline creatinine $(\mathrm{mg} / \mathrm{dL})$ & $1.4 \pm 1.1$ & $1.3 \pm 0.8$ & $1.5 \pm 1.4$ & 0.26 \\
\hline Creatinine $>2 \mathrm{mg} / \mathrm{dL}(\%)$ & 10.4 & 7.8 & 13.1 & 0.33 \\
\hline \multicolumn{5}{|l|}{ Risk Factors } \\
\hline Diabetes $(\%)$ & 36.8 & 31.3 & 42.6 & 0.19 \\
\hline Smoking history $(\%)$ & 52.0 & 48.4 & 55.7 & 0.41 \\
\hline Hypertension (\%) & 79.2 & 81.3 & 77.0 & 0.56 \\
\hline Hypercholesterolemia (\%) & 72.8 & 71.9 & 73.8 & 0.81 \\
\hline Family history of CAD (\%) & 36.0 & 39.1 & 32.8 & 0.47 \\
\hline \multicolumn{5}{|l|}{ Previous Cardiac History and Cardiac Function } \\
\hline History of CAD (\%) & 58.4 & 62.5 & 54.1 & 0.34 \\
\hline Prior thrombolysis (\%) & 3.2 & 1.6 & 4.9 & 0.29 \\
\hline Prior PCI (\%) & 21.6 & 28.1 & 14.8 & 0.07 \\
\hline Prior CABG $(\%)$ & 0.8 & 0.0 & 1.6 & 0.30 \\
\hline $\mathrm{EF}$ & $49.3 \pm 15.2$ & $52.2 \pm 13.8$ & $46.1 \pm 16.0$ & 0.02 \\
\hline $\mathrm{EF} \leq 35 \%(\%)$ & 23.2 & 15.6 & 31.1 & 0.04 \\
\hline Mitral regurgitation $\geq 2+(\%)$ & 26.4 & 18.8 & 24.6 & 0.43 \\
\hline \multicolumn{5}{|l|}{ Indications for intervention } \\
\hline Stable angina $(\%)$ & 16.0 & 17.2 & 14.8 & 0.71 \\
\hline ST-elevation MI (\%) & 10.4 & 10.9 & 9.8 & 0.84 \\
\hline Non-ST-elevation MI (\%) & 60.0 & 60.9 & 59.0 & 0.83 \\
\hline Unstable angina (\%) & 8.8 & 7.8 & 9.8 & 0.69 \\
\hline Cardiogenic shock (\%) & 18.4 & 17.2 & 19.7 & 0.72 \\
\hline Non-surgical candidate $(\%)$ & 50.4 & 53.1 & 47.5 & 0.53 \\
\hline Parsonnet score & $22.1 \pm 22.6$ & $22.1 \pm 21.9$ & $22.2 \pm 23.6$ & 0.98 \\
\hline Euroscore (Logistic) & $17.0 \pm 16.6$ & $15.7 \pm 15.8$ & $18.3 \pm 17.5$ & 0.39 \\
\hline Euroscore (Additive) & $8.5 \pm 3.9$ & $8.3 \pm 3.7$ & $8.7 \pm 4.2$ & 0.54 \\
\hline $\begin{array}{l}\text { Northern New England In-hospital Predicted } \\
\text { Mortality Probabilities for PCI }\end{array}$ & $13.3 \pm 21.8$ & $10.8 \pm 18.3$ & $16.0 \pm 24.8$ & 0.18 \\
\hline $\begin{array}{l}\text { Northern New England In-hospital Predicted } \\
\text { Mortality Probabilities for CABG }\end{array}$ & $8.6 \pm 9.2$ & $8.0 \pm 9.1$ & $9.3 \pm 9.3$ & 0.4 \\
\hline \multicolumn{5}{|l|}{ Priority Indication } \\
\hline Elective (\%) & 12.8 & 9.4 & 16.4 & 0.41 \\
\hline Urgent (\%) & 64.0 & 68.8 & 59.0 & \\
\hline Emergent $(\%)$ & 23.2 & 21.9 & 24.6 & \\
\hline
\end{tabular}


Table 2. Procedural Data for all Patients and Comparison of Bifurcation and Non-Bifurcation Cohorts

\begin{tabular}{|c|c|c|c|c|}
\hline Variables & All & Bifurcation & Non-bifurcation & P-value \\
\hline Number $(\mathrm{N}=125)$ & $125(100 \%)$ & $64(51.2 \%)$ & $61(48.8 \%)$ & \\
\hline IVUS use (\%) & 72.8 & 70.3 & 75.4 & 0.52 \\
\hline IABP use $(\%)$ & 45.6 & 50.0 & 41.0 & 0.31 \\
\hline \# of diseased vessels & $2.4 \pm 0.9$ & $2.6 \pm 0.7$ & $2.2 \pm 1.0$ & 0.01 \\
\hline 3 vessel disease $(\%)$ & 63.2 & 73.4 & 52.5 & 0.02 \\
\hline Total stent count & $3.0 \pm 2.0$ & $3.6 \pm 2.0$ & $2.3 \pm 1.8$ & $<0.001$ \\
\hline Left main stent count & $1.7 \pm 0.8$ & $2.3 \pm 0.7$ & $1.1 \pm 0.3$ & $<0.001$ \\
\hline Heparin use (\%) & 78.4 & 84.4 & 72.1 & 0.10 \\
\hline $\mathrm{IIb} / \mathrm{IIIa}$ inhibitor use (\%) & 26.4 & 35.9 & 16.4 & 0.01 \\
\hline Bivalirudin use (\%) & 41.6 & 32.8 & 50.8 & 0.04 \\
\hline \multicolumn{5}{|l|}{ Bifurcation stenting technique } \\
\hline Angioplasty rescue (\%) & & 30.2 & & \\
\hline Crush stent $(\%)$ & & 15.9 & & \\
\hline Culotte stent $(\%)$ & & 20.6 & & \\
\hline Double barrel stent (\%) & & 6.3 & & \\
\hline Single stent $(\%)$ & & 3.2 & & \\
\hline T stent $(\%)$ & & 20.6 & & \\
\hline V stent $(\%)$ & & 1.6 & & \\
\hline Y stent $(\%)$ & & 1.6 & & \\
\hline
\end{tabular}

done on significant de novo unprotected LMCA lesions $(>$ $50 \%$ diameter) between January 2005 and December 2008. An unprotected lesion was defined as one where the patient either had not had prior CABG, had a bypass but no patent grafts to the left coronary system, or the bypass graft was to the right coronary artery only. In this time frame, 221 interventions were done to LMCA lesions, 95 cases were excluded for being protected, and one case was excluded as it was a thrombectomy without any stenting. The final cohort was 125 patients. Only one patient had a prior CABG, which was to the right coronary artery.

The decision to perform PCI-stenting versus CABG was dependent upon patient co-morbidities, urgency, adequate surgical targets, patient preference, or physician preference.
In the majority of cases, there were discussions between the cardiologists and cardiothoracic surgeons regarding optimal therapy and surgical candidacy. The use of intravascular ultrasound (IVUS), intra-aortic balloon pump (IABP), and treatment of lesions including bifurcation lesions were left up to the preference of the interventional cardiologists.

Patients were followed for clinical outcomes: new MI, target vessel revascularization (TVR), any revascularization, and death.

\section{Statistical analysis}

Means for continuous variables are calculated for different groups ( $\pm 1 \mathrm{SD})$ and compared with Student's t-tests or test 


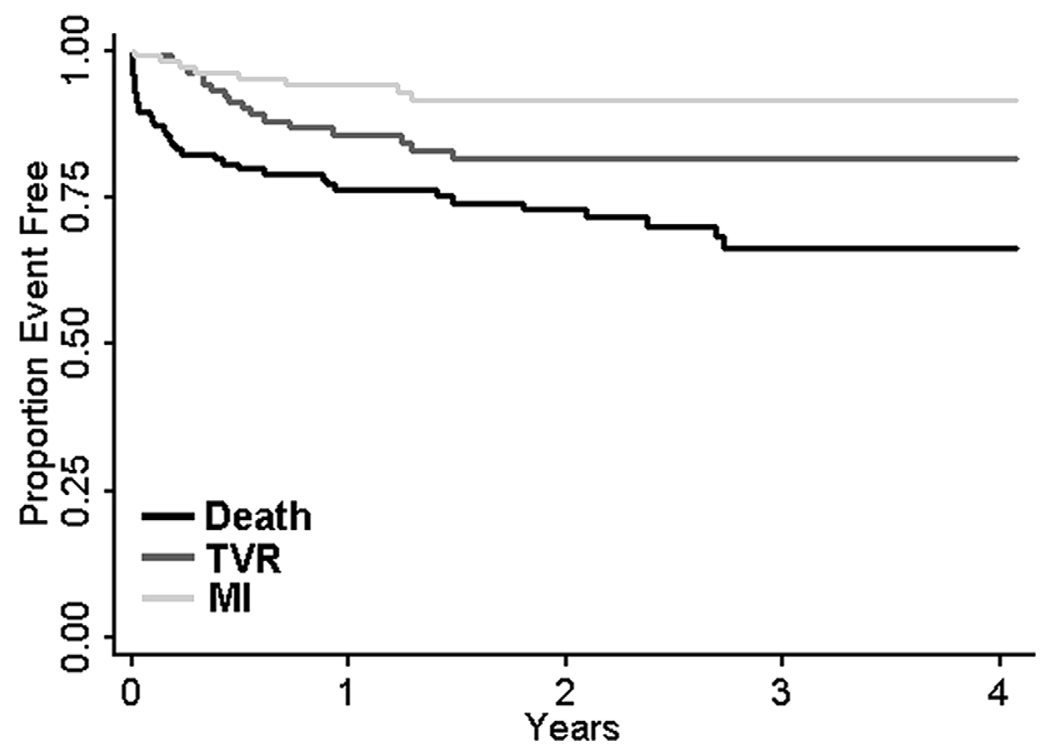

Figure 1. Kaplan-Meier graph of outcomes for left main percutaneous coronary intervention. Kaplan-Meier outcomes curves for individual and composite outcomes: death, target vessel revascularization (TVR), and myocardial infarction (MI) for patients undergoing left main coronary artery intervention.

of trend where appropriate. Binary variables are presented as percentages and compared with chi-square testing or Fisher's exact test where appropriate. Statistical significance was established at the 0.05 alpha level. Surgical and PCI predicted risk scores were calculated using published models [21-23]. Kaplan-Meier outcomes and survival curves were done with adjustment by the Ghali Method with analysis by log-rank test. Cox's proportional hazard model was used to determine crude and adjusted hazard ratios with Breslow Method for ties, adjusting for the variables with significant crude hazard ratios: $\mathrm{EF} \leq 35 \%$, left main bifurcation, IABP use, Parsonnet score, Euroscore, cardiogenic shock, positive troponin, and emergent priority. Analyses were performed using Stata 10.0 (College Station, TX).

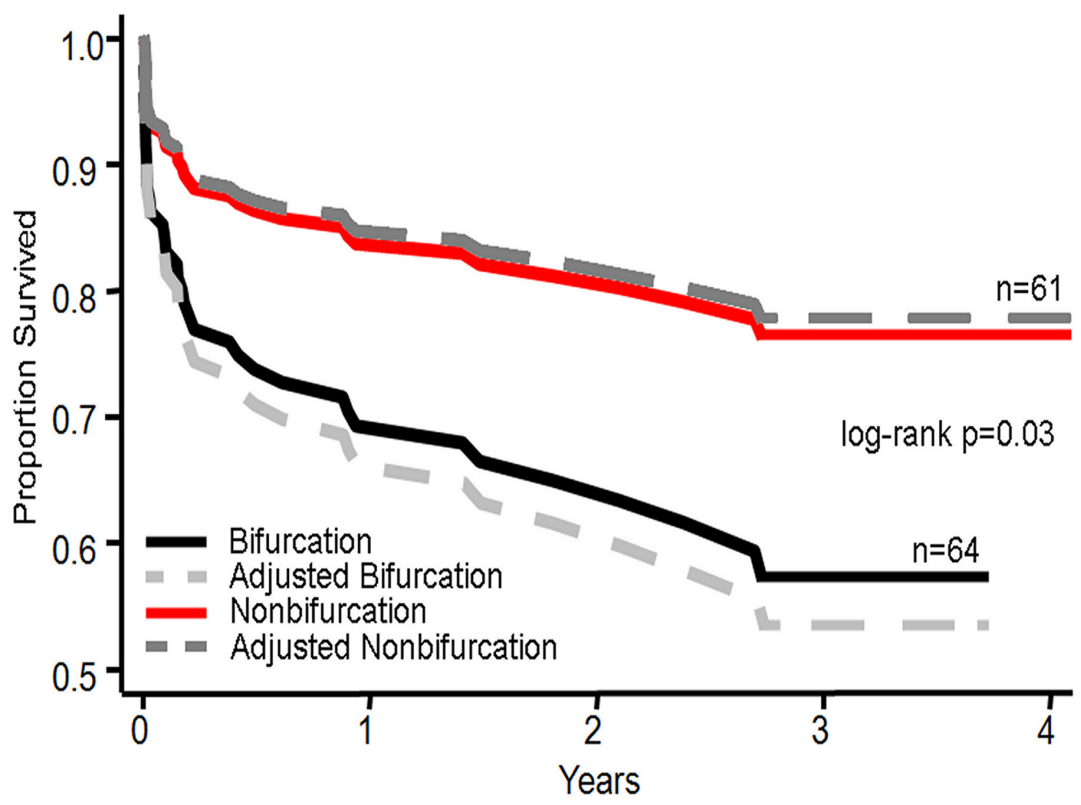

Figure 2. Risk adjusted Kaplan-Meier graph of survival for left main percutaneous coronary intervention by bifurcation or nonbifurcation. Risk adjusted Kaplan-Meier survival curve by for bifurcation and nonbifurcation with log-rank analysis adjusted for age, CHF, EF $\leq 35$, cardiogenic shock, and creatinine $>2$. 
Table 3. Outcomes for all Patients and Comparison of Bifurcation and Non-Bifurcation Cohorts

\begin{tabular}{lllll}
\hline Variables & All & Bifurcation & Non-bifurcation & P-value \\
\hline Number $(\mathrm{N}=125)$ & $125(100 \%)$ & $64(51.2 \%)$ & $61(48.8 \%)$ & 0.07 \\
Mean follow-up (years) & $1.8 \pm 1.2$ & $1.6 \pm 1.2$ & $1.9 \pm 1.3$ & 0.03 \\
Mortality (\%) & 28.8 & 37.5 & 19.7 & 0.14 \\
$\begin{array}{l}\text { In-hospital mortality } \\
\text { Any revascularization (\%) }\end{array}$ & 21.6 & 12.5 & 4.9 & 0.17 \\
TVR (\%) & 13.6 & 26.6 & 16.4 & 0.88 \\
MI (\%) & 7.2 & 14.1 & 13.1 & 0.79 \\
$\begin{array}{l}\text { Mean time to death (years) } \\
\text { Mean time to TVR (years) }\end{array}$ & $0.6 \pm 0.8$ & 7.8 & 6.6 & 0.62 \\
$\begin{array}{l}\text { Mean time to any } \\
\text { revascularization (years) }\end{array}$ & $0.6 \pm 0.4$ & $0.6 \pm 0.9$ & $0.5 \pm 0.8$ & 0.03 \\
\hline
\end{tabular}

\section{Results}

\section{Study participants}

Patient characteristics are presented in Table 1, and proce- dural data is presented in Table 2. Continuous variables are presented with means $\pm 1 \mathrm{SD}$. Mean patient follow-up was 1.8 years with longest follow-up of 4.1 years. A prior history of CAD was present in $58 \%$ of patients: one patient had a prior $\mathrm{CABG}$ and $21.6 \%$ of patients had a prior PCI, $50.4 \%$ of

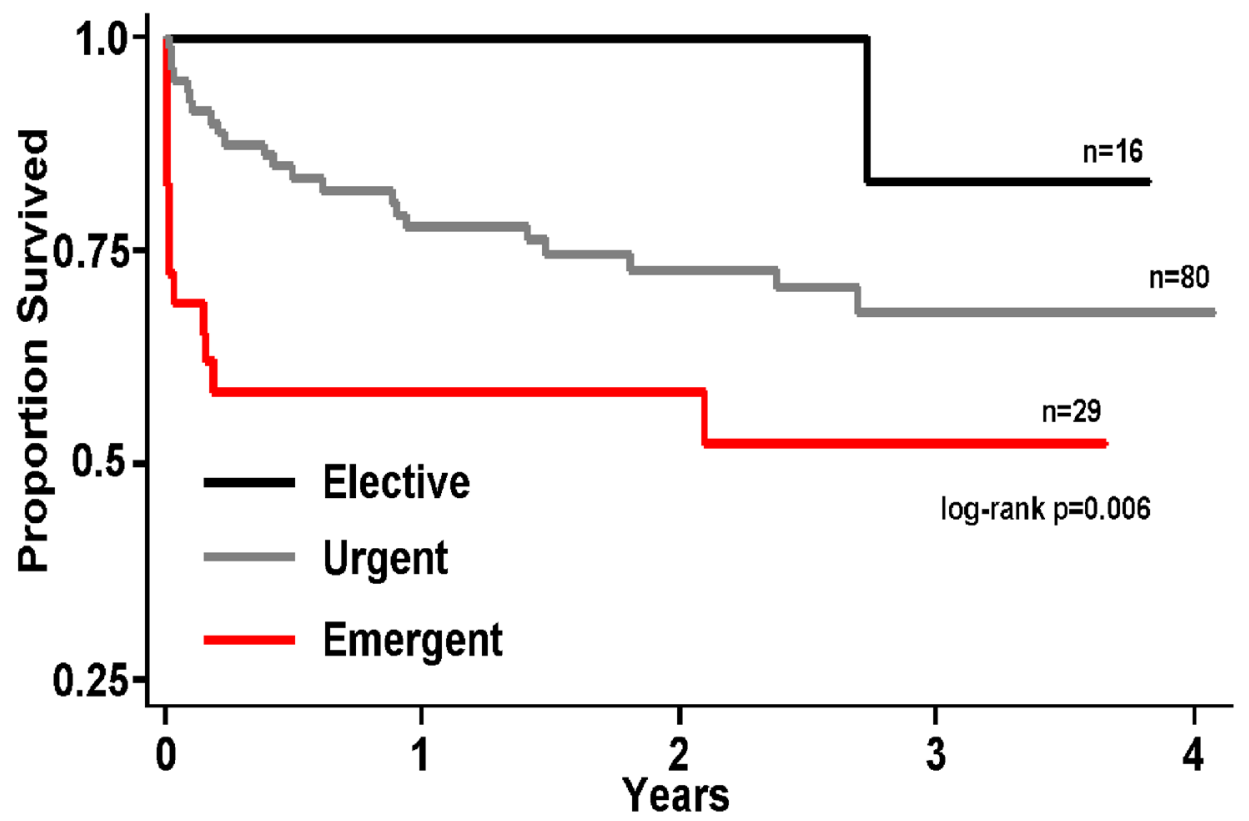

Figure 3. Kaplan-Meier graph of survival for left main percutaneous coronary intervention by priority. Kaplan-Meier survival curve by priority designation: elective, urgent, and emergent with log-rank analysis. 
Table 4. Crude and Adjusted Hazard Ratios

\begin{tabular}{|c|c|c|c|c|}
\hline Risk Factor & Crude HR & $95 \% \mathrm{CI}$ & Adjusted HR & $95 \%$ CI \\
\hline $\mathrm{EF}<35$ & 2.33 & $(1.18-4.60)$ & 2.44 & $(1.10-5.42)$ \\
\hline LM bifurcation & 2.07 & $(1.03-4.14)$ & 2.65 & $(1.24-5.67)$ \\
\hline IABP & 3.73 & $(1.80-7.74)$ & 1.67 & $(0.67-4.13)$ \\
\hline Parsonnet Score & 1.03 & $(1.02-1.04)$ & 1.03 & $(1.00-1.05)$ \\
\hline Euroscore & 1.04 & $(1.02-1.06)$ & 1.00 & $(0.97-1.03)$ \\
\hline Cardiogenic Shock & 3.00 & $(1.47-6.12)$ & 0.64 & $(0.18-2.28)$ \\
\hline Positive Troponin & 3.27 & $(1.27-8.41)$ & 1.90 & $(0.69-5.26)$ \\
\hline Emergent & 2.54 & $(1.29-5.02)$ & 1.11 & $(0.39-3.17)$ \\
\hline
\end{tabular}

patients were non-surgical candidates, 3-vessel disease was present in $63.2 \%$ of individuals. Cases were either urgent or emergent $87.2 \%$ of the time. By using an additive Euroscore value of 6 or more, $74.4 \%$ of patients were considered to be at high surgical risk. On average, 2.69 lesions were treated per case with an average of 3.0 stents used. Survival was $89.6 \%$ at 30 days, $76.8 \%$ at 1 year, and $71.2 \%$ at 4 years (Fig. 1) with a cumulative TVR rate of $13.6 \%$.

\section{Bifurcation vs. non-bifurcation lesions}

The $51.2 \%$ of cases involved bifurcation of the LMCA. Baseline data for bifurcation and non-bifurcation groups are presented in Table 1 . The only significantly different characteristic was EF, with the bifurcation group having a higher mean EF than non-bifurcation group (52.2 vs. 46.1). Patients with lesions treated at the LMCA bifurcation had an increased mortality rate compared to non-bifurcation lesions (37.5\% compared to $19.7 \%)$. Adjusting for covariates further strengthened the mortality difference between the two groups (Fig. 2). There was also a nonsignificant trend towards higher in-hospital mortality $(12.5 \%$ versus $4.9 \%)$. There was no significant difference between cumulative MI or TVR rates. However, there was a non-significant trend of more revascularizations in the bifurcation group $(26.6 \%$ compared to $16.4 \%$ ).

\section{Priority designation}

With increasing urgency, there was an overall decline in EF (elective 59.4\%, urgent 51.6\%, emergent 38.0\%). Many emergent patients were in shock $(62.1 \%)$ and not surgical candidates $(89.7 \%)$. The urgent and emergent groups were more likely to have a positive troponin, acute coronary syndrome, ST-elevation MI and Non-ST-elevation MI, and be in cardiogenic shock. The more emergent procedures had higher risk with higher Parsonnet and Euroscores, and these procedures were more likely to have IABP utilized. Heparin and IIb/IIIa inhibitors were more likely to be utilized in the emergent cases, whereas bivalirudin was more likely to be used in elective cases. With increasing urgency of the procedure, there was an increase in the cumulative mortality (elective 6.3\%, urgent 26.3\%, emergent 44.8\%) (Fig. 3 ). The emergent group had the highest 30-day mortality at $31.0 \%$. Elective and urgent patients had in-hospital mortality comparable to expected mortality when looking at PCI risk models with the elective group at expected and the urgent group mortality $7 \%$ better than expected. The emergent group had $40 \%$ higher than expected mortality. There was no significant difference between myocardial infarction rates, TVR, or any revascularization between the three priority groups.

\section{Analysis of risk factors for mortality}

Cox proportional hazard regression models were utilized to analyze risk factors for mortality. Independent risk factors for mortality were found to be $\mathrm{EF} \leq 35 \%$ (HR 2.44) and left main bifurcation lesions (HR 2.65) (Table 4). Other factors such as IABP use, high Parsonnet score and Euroscore, cardiogenic shock, positive troponin, and emergent priority had significant crude hazard ratios, but these did not result in 
independently significant ratios in the adjusted hazard ratio model. Of note, stent count, mitral regurgitation $\geq 2+$, and acute coronary syndrome were not found to be significant risk factors.

\section{Discussion}

The purpose of the present study was to analyze patients who underwent PCI-stenting of the LMCA in a real world application. Our longest patient follow-up was 4 years with a mean follow-up of 1.8 years. Mortality was $10.4 \%$ at 30 days, $23.2 \%$ at 1 year, and $28.8 \%$ at 4 years. Cumulative TVR rate was $13.6 \%$. Our study illustrates the viability of PCI-stenting as a treatment option in patients with LMCA stenosis.

Our survival rates are lower than that presented from long-term outcomes from CABG presented in the CASS (Coronary Artery Surgery Study) trial, where they had 10\% mortality at 5 years and $26 \%$ at 10 years [6].

Several recent trials have presented outcomes on ULMCA PCI [24-27]. A recent meta-analysis of these randomized trials showed no significant difference in MACCE, death, MI when PCI compares with CABG at 1 year [28]. PCI results in higher repeat revascularization rates but lower stroke rates than $\mathrm{CABG}$.

In comparison to these trials, our mortality rate is higher. Our population represents a real-world application of ULMCA PCI. Our population was at higher risk as evidenced by higher Parsonnet and Euroscores. Patients in our elective priority group had surgical risk score similar to those seen in the SYNTAX trial. This group also had similar cumulative mortality to that seen in SYNTAX at a rate of $6.3 \%$. Our 4 year mortality of $28.8 \%$ compares favorably to recent large registry real world data mortality at 30 months of $42.7 \%$ [29].

In our study, bifurcation of the LMCA was found to be an independent predictor of mortality. A recent registry also found an increase in major adverse cardiac events at 2 years with patients with bifurcation lesions [30]. Bifurcation lesions treated with double-stent techniques had worse outcomes at 1 year. Single stent technique was utilized in $33.4 \%$ of patients in our study with bifurcation lesions. However, there was no significant difference in outcomes when compared to 2 stent techniques.

$\mathrm{EF} \leq 35 \%$ was also found to be an independent risk factor for increased mortality. These patient characteristics help further risk stratify patients and may ultimately guide in patient selection for LMCA stenting.

\section{Limitations}

This is an observational study. As such, we cannot determine cause-effect relationships and can only suggest associations. Another limitation is our modest sample size which is a di- rect result of PCI of the LMCA being a relatively rare intervention. This does decrease the power of analyses. Personal operator preference was used with each intervention resulting in variability in the techniques used to treat each lesion, number of stents, stent type, as well as use of IVUS. This makes the comparison of each case difficult and can lead to confounding. The degree and timing of complete revascularization was also not looked at. We also did not look at the types of stents used; while the great majority of stents were DES, some of the interventions utilized bare-metal stents. DES may result in improved outcomes compared to baremetal stents [29, 31].

\section{Conclusions}

PCI of the LMCA remains a viable treatment option for patients in the drug-eluting stent era. It extends options in patients whom are poor candidates for coronary artery bypass grafts. Furthermore, elective LMCA PCI in low-risk CABG patients results in good survival rates. LMCA PCI is associated with a high restenosis rate of $13.6 \%$. EF $\leq 35 \%$ and $\mathrm{LM}$ bifurcation were independent risk factors for mortality. Further studies regarding appropriate patient selection as well as procedural techniques regarding revascularization should be done to better define which patients may derive the best benefit from ULMCA PCI.

\section{Disclosures}

Craig A. Thompson has served as consultant for Abbott Vascular, Bridgepoint Medical, InfraRedx, Medtronic, SanofiAventis.

\section{References}

1. Proudfit WL, Shirey EK, Sones FM, Jr. Distribution of arterial lesions demonstrated by selective cinecoronary arteriography. Circulation. 1967;36(1):54-62.

2. Cohen MV, Cohn PF, Herman MV, Gorlin R. Diagnosis and prognosis of main left coronary artery obstruction. Circulation. 1972;45(1 Suppl):I57-65.

3. Elliot JM, Jackson NW, Doogue MP, Smyth DW. Has the prognosis of left main (LM) and left main equivalent (LMEQ) coronary disease changed: Analysis of a long waiting list. J Am Coll Cardiol 1988; 31: 214A.

4. Takaro T, Peduzzi P, Detre KM, Hultgren HN, Murphy ML, van der Bel-Kahn J, Thomsen J, et al. Survival in subgroups of patients with left main coronary artery disease. Veterans Administration Cooperative Study of Surgery for Coronary Arterial Occlusive Disease. Circulation. 1982;66(1):14-22.

5. Chaitman BR, Fisher LD, Bourassa MG, Davis K, Rog- 
ers WJ, Maynard C, Tyras DH, et al. Effect of coronary bypass surgery on survival patterns in subsets of patients with left main coronary artery disease. Report of the Collaborative Study in Coronary Artery Surgery (CASS). Am J Cardiol. 1981;48(4):765-777.

6. Caracciolo EA, Davis KB, Sopko G, Kaiser GC, Corley SD, Schaff H, Taylor HA, et al. Comparison of surgical and medical group survival in patients with left main equivalent coronary artery disease. Long-term CASS experience. Circulation. 1995;91(9):2335-2344.

7. Myers WO, Blackstone EH, Davis K, Foster ED, Kaiser GC. CASS Registry long term surgical survival. Coronary Artery Surgery Study. J Am Coll Cardiol. 1999;33(2):488-498.

8. Kushner FG, Hand M, Smith SC, Jr., King SB, 3rd, Anderson JL, Antman EM, Bailey SR, et al. 2009 focused updates: ACC/AHA guidelines for the management of patients with ST-elevation myocardial infarction (updating the 2004 guideline and 2007 focused update) and ACC/AHA/SCAI guidelines on percutaneous coronary intervention (updating the 2005 guideline and 2007 focused update) a report of the American College of Cardiology Foundation/American Heart Association Task Force on Practice Guidelines. J Am Coll Cardiol. 2009;54(23):2205-2241.

9. Park SJ, Hong MK, Lee CW, Kim JJ, Song JK, Kang DH, Park SW, et al. Elective stenting of unprotected left main coronary artery stenosis: effect of debulking before stenting and intravascular ultrasound guidance. J Am Coll Cardiol. 2001;38(4):1054-1060.

10. Park SJ, Park SW, Hong MK, Lee CW, Lee JH, Kim JJ, Jang YS, et al. Long-term (three-year) outcomes after stenting of unprotected left main coronary artery stenosis in patients with normal left ventricular function. Am J Cardiol. 2003;91(1):12-16.

11. Takagi T, Stankovic G, Finci L, Toutouzas K, Chieffo A, Spanos V, Liistro F, et al. Results and long-term predictors of adverse clinical events after elective percutaneous interventions on unprotected left main coronary artery. Circulation. 2002;106(6):698-702.

12. Tan WA, Tamai H, Park SJ, Plokker HW, Nobuyoshi M, Suzuki T, Colombo A, et al. Long-term clinical outcomes after unprotected left main trunk percutaneous revascularization in 279 patients. Circulation. 2001;104(14):1609-1614.

13. Moses JW, Leon MB, Popma JJ, Fitzgerald PJ, Holmes DR, O'Shaughnessy C, Caputo RP, et al. Sirolimuseluting stents versus standard stents in patients with stenosis in a native coronary artery. $\mathrm{N}$ Engl J Med. 2003;349(14):1315-1323.

14. Stone GW, Ellis SG, Cox DA, Hermiller J, O'Shaughnessy C, Mann JT, Turco M, et al. A polymerbased, paclitaxel-eluting stent in patients with coronary artery disease. N Engl J Med. 2004;350(3):221-231.
15. Stettler C, Wandel S, Allemann S, Kastrati A, Morice MC, Schomig A, Pfisterer ME, et al. Outcomes associated with drug-eluting and bare-metal stents: a collaborative network meta-analysis. Lancet. 2007;370(9591):937948.

16. Chieffo A, Morici N, Maisano F, Bonizzoni E, Cosgrave J, Montorfano M, Airoldi F, et al. Percutaneous treatment with drug-eluting stent implantation versus bypass surgery for unprotected left main stenosis: a single-center experience. Circulation. 2006;113(21):2542-2547.

17. Lee MS, Kapoor N, Jamal F, Czer L, Aragon J, Forrester $\mathrm{J}$, Kar S, et al. Comparison of coronary artery bypass surgery with percutaneous coronary intervention with drug-eluting stents for unprotected left main coronary artery disease. J Am Coll Cardiol. 2006;47(4):864-870.

18. Price MJ, Cristea E, Sawhney N, Kao JA, Moses JW, Leon MB, Costa RA, et al. Serial angiographic followup of sirolimus-eluting stents for unprotected left main coronary artery revascularization. J Am Coll Cardiol. 2006;47(4):871-877.

19. Park SJ, Kim YH, Lee BK, Lee SW, Lee CW, Hong MK, Kim JJ, et al. Sirolimus-eluting stent implantation for unprotected left main coronary artery stenosis: comparison with bare metal stent implantation. J Am Coll Cardiol. 2005;45(3):351-356.

20. Valgimigli M, Malagutti P, Aoki J, Garcia-Garcia HM, Rodriguez Granillo GA, van Mieghem CA, Ligthart JM, et al. Sirolimus-eluting versus paclitaxel-eluting stent implantation for the percutaneous treatment of left main coronary artery disease: a combined RESEARCH and T-SEARCH long-term analysis. J Am Coll Cardiol. 2006;47(3):507-514.

21. Nashef SA, Roques F, Michel P, Gauducheau E, Lemeshow S, Salamon R. European system for cardiac operative risk evaluation (EuroSCORE). Eur J Cardiothorac Surg. 1999;16(1):9-13.

22. Roques F, Michel P, Goldstone AR, Nashef SA. The logistic EuroSCORE. Eur Heart J. 2003;24(9):881-882.

23. Parsonnet V, Dean D, Bernstein AD. A method of uniform stratification of risk for evaluating the results of surgery in acquired adult heart disease. Circulation. 1989;79(6 Pt 2):I3-12.

24. Serruys PW, Morice MC, Kappetein AP, Colombo A, Holmes DR, Mack MJ, Stahle E, et al. Percutaneous coronary intervention versus coronary-artery bypass grafting for severe coronary artery disease. N Engl J Med. 2009;360(10):961-972.

25. Buszman PE, Buszman PP, Kiesz RS, Bochenek A, Trela B, Konkolewska M, Wallace-Bradley D, et al. Early and long-term results of unprotected left main coronary artery stenting: the LE MANS (Left Main Coronary Artery Stenting) registry. J Am Coll Cardiol. 2009;54(16):15001511.

26. Montalescot G, Brieger D, Eagle KA, Anderson FA, Jr., 
FitzGerald G, Lee MS, Steg PG, et al. Unprotected left main revascularization in patients with acute coronary syndromes. Eur Heart J. 2009;30(19):2308-2317.

27. Boudriot E, Thiele H, Walther T, Liebetrau C, Boeckstegers P, Pohl T, Reichart B, et al. Randomized comparison of percutaneous coronary intervention with sirolimuseluting stents versus coronary artery bypass grafting in unprotected left main stem stenosis. J Am Coll Cardiol. 2011;57(5):538-545.

28. Capodanno D, Stone GW, Morice MC, Bass TA, Tamburino C. Percutaneous coronary intervention versus coronary artery bypass graft surgery in left main coronary artery disease: a meta-analysis of randomized clinical data. J Am Coll Cardiol. 2011;58(14):1426-1432.

29. Brennan JM, Dai D, Patel MR, Rao SV, Armstrong EJ, Messenger JC, Curtis JP, et al. Characteristics and long-term outcomes of percutaneous revascularization of unprotected left main coronary artery stenosis in the United States: a report from the National Cardiovascular Data Registry, 2004 to 2008. J Am Coll Cardiol. 2012;59(7):648-654.

30. Chen SL, Ye F, Zhang JJ, Liu ZZ, Lin S, Zhu ZS, Sun $\mathrm{XW}$, et al. Distal left main coronary bifurcation lesions predict worse outcome in patients undergoing percutaneous implantation of drug-eluting stents: results from the Drug-Eluting Stent for the Treatment of Left Main Disease (DISTAL) Study. Cardiology. 2009;113(4):264-273.

31. Kim YH, Park DW, Lee SW, Yun SC, Lee CW, Hong MK, Park SW, et al. Long-term safety and effectiveness of unprotected left main coronary stenting with drugeluting stents compared with bare-metal stents. Circulation. 2009;120(5):400-407. 